\title{
Erratum to: How we wrote a landmark nasopharyngeal intergroup phase III protocol in North America
}

\author{
Muhyi Al-Sarraf
}

Published online: 30 June 2012

(C) Springer-Verlag 2012

Erratum to: J Radiat Oncol

DOI 10.1007/s13566-012-0022-2

The category was given incorrectly

The correct rendering is Review

The online version of the original article can be found at http://dx.doi.org/ 10.1007/s13566-012-0022-2

M. Al-Sarraf $(\bowtie)$

William Beaumont Hospital,

Royal Oak, MI, USA

e-mail: mealsarraf@aol.com

M. Al-Sarraf

Department of Medicine,

2810 Birchwood CT,

Bloomfield Hills, MI 48302-0900, USA 